\title{
Conservative treatment and natural history of acute lumbar disc lesions
}

\author{
JOHN PEARCE AND J. M. H. MOLL \\ From the Neurological Departments of The General Infirmary at Leeds and Pinderfields General \\ Hospital, Wakefield
}

Lesions of the intervertebral discs are the commonest identifiable cause of acute back pain and sciatica. Chronic degenerative lesions of the intervertebral discs, and of the intervertebral facets and ligaments, may be responsible for some examples of longstanding backache. So common, however, are psychoneurotic features, compensation claims, and other motivating factors in the presence of minor radiological changes, which often do not correlate with the clinical features, that the evaluation of chronic backache is extremely difficult.

Despite the fact that the acute lumbar disc lesion is extremely common, its natural history has never been adequately studied. Numerous studies of the pathological and anatomical basis of the syndrome have been reported (Saunders and Inman, 1940; Bradford and Spurling, 1947; Friberg and Hirsch, 1950), and there are many accounts of the role of surgical treatment, including those of Spurling and Grantham (1949), O'Connell (1950), and Decker and Shapiro (1957). However, it is remarkable that the literature contains few papers reporting the results of conservative treatment, and the evaluation of some of the many forms of therapy which are commonly used.

Conservative treatment includes such non-operative measures as spinal traction, manipulation, plaster of Paris spinal jackets and Goldthwait lumbar supports, and strict rest in bed alone.

Of these measures there is no doubt that absolute rest in bed is the simplest, requiring no apparatus, and is also the safest, avoiding the cord damage, often irreversible, which is known to occur occasionally as a sequel to spinal traction or manipulation. It is not the purpose of this paper to assess forms of treatment other than simple rest in bed, since no relevant scientific data are available. If clinical experience is of any value it is the opinion of many authorities that spinal manipulation, although producing unpredictable and occasionally dramatic cures, is often of no benefit and can be frankly dangerous. Similarly, there is no real evidence that traction does any more than keep the patient still and at strict rest in bed. Since it is common experience that rest in bed is effective in some patients with acute disc lesions (Larson, 1957; Roseman, 1958; Jennett, 1964; Armstrong, 1965) it was decided to attempt an assessment of this procedure.

\section{MATERIALS AND METHODS}

This study includes all patients admitted consecutively to the Neurological Unit of Pinderfields General Hospital within the last 13 years with a diagnosis of acute lumbar disc lesions. Patients were excluded on account of chronic back pain of uncertain nature, and patients in whom a strong neurotic element obscured the organic findings or made objective assessment impossible. Patients were also excluded for submission to early surgery on account of intractable pain after one to two months of absolute rest in bed; evidence of compression of the cauda equina with sphincter involvement (Jennett, 1956); and, diagnostic doubt if clinical or myelographic evidence left the suspicion of a spinal tumour.

Ninety-one patients were included, in all of whom the diagnosis had been made by a consultant neurologist (Dr. Hugh Garland), and at follow-up no case of spinal or pelvic tumour (which can on occasion mimic a disc lesion) was found. Thirty-eight patients were suffering from a first episode, and 53 suffered a recurrence, having had one or more acute episodes in the past. In all patients, however, the present episode was of abrupt onset occurring at a time the patient could clearly define. Restricted spinal flexion and straight leg raising were present initially, and signs of root compression were evident in many patients.

The method of treatment employed was the same for all patients. They were admitted to hospital and after the initial examination and investigations were completed they were confined to bed for 24 hours per day for two weeks. The mattress was placed on wooden fracture boards and only one pillow was permitted. If difficulty was experienced with bedpans the patient was assisted to use a bedside commode, but this was the only time he was allowed out of bed. After two weeks, if free of pain, the patient was gradually mobilized during the next week. If pain or restriction of straight leg raising persisted, absolute rest in bed was instituted for a further seven to 14 days. When walking in the hospital was possible without pain the patient was discharged and advised to return 
to work within the next few weeks at his general practitioner's discretion. Patients were told not to bend with the knees extended or to lift heavy objects for three months.

Fifty-three patients were interviewed and examined on average eight years (range 0-13) after the acute episode: these are designated group A. Despite repeated attempts 38 patients would not or could not be reexamined, but answers to a carefully worded questionnaire (see Appendix) were obtained from 20 patients who constitute group $B$.

It was decided to analyse the results of the groups independently, but if they shared a high degree of similarity the results would be finally assessed together. Despite the limitations of an enquiry by questionnaire, the questions are very simple and give only the objective facts concerning the occurrence of subsequent pain and disability. This is considered worthy of record and preferable to discarding in toto the results in this group, which would itself prejudice the assessment of the results.

\section{RESULTS}

Separate analyses of group A (assessed at interview and examination) and group $\mathbf{B}$ are considered. Sixty-eight patients (group A 48, group B 20) were studied. The results are presented in Tables I-VI. Five patients were subjected to surgery after their first admission and are excluded from the analysis of conservative treatment, but as failures of such are considered further in the discussion.

SEVERITY OF CHRONIC SYMPTOMS These observations were recorded as absent, mild, moderate, or severe. The degree of severity of pain was based on the patient's assessment.

TABLE I

\begin{tabular}{lccc} 
Degree & $\begin{array}{c}\text { SEVERITY OF PERSISTING } \\
\text { Absent }\end{array}$ & Mild & $\begin{array}{l}\text { PAIN } \\
\text { Moderate or Severe }\end{array}$ \\
\hline $\begin{array}{l}\text { Group A } \\
\text { (total 48) }\end{array}$ & $11(23 \%)$ & $22(45 \%)$ & $15(23 \%)$ \\
$\begin{array}{l}\text { Group B } \\
\text { (total 20) }\end{array}$ & $7(35 \%)$ & $6(30 \%)$ & $7(35 \%)$ \\
$\begin{array}{l}\text { Groups A and B } \\
\text { combined } \\
\text { (total 68) }\end{array}$ & $18(26.5 \%)$ & $28(41.1 \%)$ & $22(32.4 \%)$ \\
\end{tabular}

It can be seen from Table I that $26.5 \%$ of the patients at the time of follow-up interview were found to be completely free from pain, $41 \%$ were still troubled by mild pain, while $32.4 \%$ were having moderate or severe pain.

SEVERITY OF RECURRENCE IN ACUTE EXACERBATIONS Observations were made of the recurrence of pain necessitating a period of rest in bed or loss of work. It was decided to use the number of weeks lost from work per year as an index of severity. Accordingly, the following arbitráry scheme was used:-Nil, no work loss; mild, less than four weeks/year work loss; moderate, four to eight weeks/year work loss; severe, more than eight weeks/year work loss.

The recurrence rate is presented in Table II. There was no recurrence in $57 \%$ of patients, the recurrence was mild in $19 \%$, and moderate or severe in $24 \%$ of patients.

PHYSICAL SIGNS These results were obtained (group A only) by comparing the physical findings at the time of follow-up with those recorded immediately before the period of strict rest in bed. The results were grouped as regression, no change, or progression. Observations included limitation of spinal flexion and straight leg raising, motor or sensory dysfunction, tendon reflex change, and muscle wasting. Table III shows that $60 \%$ of the patients were found to have some degree of improvement, $21 \%$ were unchanged, and $19 \%$ showed progression of the physical signs.

TABLE III

PHYSICAL SIGNS

\begin{tabular}{lccc} 
& Regressed & Same & Progressed \\
\hline $\begin{array}{l}\text { Group A } \\
\text { (total 48) }\end{array}$ & $29(60 \%)$ & $10(21 \%)$ & $9(19 \%)$
\end{tabular}

WORKING CAPACITY The effect of persisting symptoms on working capacity was recorded simply as unchanged or diminished (Table IV). At the time of interview $71 \%$ of patients were still doing the same

TABLE II

Severity of Recurrence
Work Loss
(weeks/year)
Group A
(total 48)
Group B
(total 20)
Groups A and B combined
(total 68 )

Severity of Recurrence

Loss

(total 20)

(total 68)
SEVERITY OF RECURRENCE IN ACUTE EXACERBATIONS

\begin{tabular}{|ccccc} 
Nil & Mild & Moderate & Severe & $\begin{array}{c}\text { Moderate and severe } \\
\text { combined }\end{array}$ \\
\hline 0 & 4 & $4-8$ & 8 & \\
\hline $28(58 \%)$ & $11(23 \%)$ & $4(8 \%)$ & $5(11 \%)$ & $9(19 \%)$ \\
$11(55 \%)$ & $2(10 \%)$ & $3(15 \%)$ & $4(20 \%)$ & $7(35 \%)$ \\
$39(57 \%)$ & $13(19 \%)$ & $7(10 \%)$ & $9(14 \%)$ & $16(24 \%)$
\end{tabular}


job. The remaining $29 \%$, because of their residual symptoms, had taken up lighter work, which in most cases involved some loss of earnings.

\section{TABLE IV}

WORKING CAPACITY

\begin{tabular}{llc} 
& Unchanged & Diminished \\
\hline $\begin{array}{l}\text { Group A } \\
\text { (total 48) }\end{array}$ & $35(73 \%)$ & $13(27 \%)$ \\
$\begin{array}{l}\text { Group B } \\
\text { (total 20) }\end{array}$ & $13(65 \%)$ & $7(35 \%)$ \\
$\begin{array}{l}\text { Groups A and B } \\
\text { combined } \\
\text { (total 68) }\end{array}$ & $48(71 \%)$ & $20(29 \%)$
\end{tabular}

FURTHER TREATMENT This excluded additional rest in bed between the initial hospital admission and the follow-up. Further conservative treatment included various forms of spinal support (usually a Goldthwait belt or a plaster jacket), traction, manipulation, and physiotherapy. Reference to Table $\mathrm{V}$ shows that $49 \%$ had had no further treatment, $44 \%$ had required one or more types of medical treatment, while the remaining $7 \%$ had undergone surgery. In general, the $44 \%$ who had further medical treatment obtained no more relief than they had had by means of rest alone. Occasional lasting relief was claimed by patients for manipulation or a plaster jacket, but conversely these measures were unsuccessful in many other patients.

\section{TABLE V}

FURTHER TREATMENT

\begin{tabular}{lccc} 
& \multicolumn{2}{c}{ Type of Treatment } \\
\cline { 2 - 4 } & Nil & Medical & Surgical \\
\hline $\begin{array}{l}\text { Group A } \\
\text { (total 53) }\end{array}$ & $23(44 \%)$ & $25(47 \%)$ & $5(9 \%)$ \\
$\begin{array}{l}\text { Group B } \\
\text { (total 20) }\end{array}$ & $13(65 \%)$ & $7(35 \%)$ & $0(0 \%)$ \\
$\begin{array}{l}\text { Groups A and B } \\
\text { combined } \\
\text { (total 73) }\end{array}$ & $36(49 \%)$ & $32(44 \%)$ & $5(7 \%)$ \\
& & & \\
\end{tabular}

\section{DISCUSSION}

Assessment of the results of conservative treatment in lumbar disc lesions is complicated by the variable and episodic nature of the pain which characterizes the syndrome.

To enable an approximate comparison between the results of our own series and those conducted previously, the results from Table I (degree of persisting chronic symptoms) have been taken as representative. It is appreciated, however, that in previous studies residual symptoms have been analysed together, there having been no clear separation between acute and chronic pain. A further difficulty arises with regard to the unavoidably arbitrary nature and minor differences in the classification of severity of symptoms. However, in most of the previously conducted series there can be recognized three broad divisions, namely, a painfree group, those with mild symptoms, and a third category in which the degree of persisting symptoms has been regarded as an unsatisfactory response to conservative treatment.

The present study shows that $26.5 \%$ (Table I) of patients were symptom-free at the time of follow-up interview. In the majority of cases freedom from symptoms had exceeded one year. These results of subjective pain, and the working disability incurred by our patients, can be compared with those of previous workers. Kirsten (1945) studied a selected series of 49 patients of whom 24 were not subjected to operation. Only $12.5 \%$ of this group were totally symptom-free, but the follow-up period was short, ranging from six months to three years; moreover, the series was highly selected. Dunning (1946) reported on 55 patients treated conservatively for sciatica attributed to lumbar disc lesions. Thirty-six per cent of these patients were free of symptoms at a follow-up examination or in response to a questionnaire. Earlier Ekvall (1939) followed up 74 patients four to five years after the onset of sciatica. Twentythree were entirely free of symptoms and a further 21 patients, although suffering from minor symptoms, were capable of hard manual labour. In 1949 Colonna and Friedenberg reported on 29 patients treated conservatively of whom $29 \%$ were free of symptoms, $71 \%$ had residual pain, and $32 \%$ were dissatisfied, implying more severe pain. The authors, guided by these results, recommended surgery for patients with lumbar disc lesions not responding quickly to conservative treatment, but in their larger series of 95 operated patients $40 \%$ had residual symptoms and $13 \%$ were dissatisfied with the results of surgery. From these and other series referred to, it is clear that surgical treatment is not the entire answer, even in carefully selected patients, to the problem of acute lumbar disc lesions.

Patients still suffering from mild symptoms, usually unassociated with work loss, comprised the largest proportion of the present series, $41 \%$. Comparison with previous studies reveals that $18 \%$ (Dunning) and $39 \%$ (Colonna and Friedenberg) of patients had chronic but mild symptoms.

Our moderate and severe chronic pain categories have been combined and will arbitrarily represent the 'unsatisfactory response' group referred to previously. In a large proportion of patients there had been loss of work or diminution of working capacity. Our figure, $32.4 \%$, approximates closely to Colonna's result of $32 \%$ but less closely to that of 
Dunning, 46\%. In Armstrong's view (1965), patients who fail to respond to conservative treatment amount to between $10 \%$ and $20 \%$ of patients seen by a surgeon.

A more objective and useful method of assessment lies in the measurement of recurrence of acute pain severe enough to necessitate a period of rest in bed or loss of working time. The period of work loss has been used as a parameter of severity according to the scheme outlined previously. We are unable to compare these results with previous work since no similar estimates have been employed in the past. In our experience this is the most useful means of assessing the results of treatment.

It was found, by means of a separate analysis, that there exists a degree of correlation between the recurrence rate of acute exacerbations and the severity of chronic residual symptoms. In other words, patients who had enjoyed absolute freedom from further acute exacerbation tended also to be free, or relatively free, from chronic pain. Similarly, those patients who had been incapacitated by several acute exacerbations also carried with them a high incidence of severe chronic symptoms. The period elapsing between initial treatment and recurrence of acute pain appeared to follow no single pattern.

It has become popular belief at the present time that most patients treated conservatively recover completely. This view is not consistent with the results of the present survey. The overall results which are shown in Table VI show a high degree of correlation between loss of work from acute symptoms, chronic symptoms, and the need to change occupation. Following conservative therapy $32.4 \%$ had serious chronic symptoms and $24 \%$ incurred serious loss of work because of acute pain. Twentynine per cent had changed their occupation because of persisting symptoms. We regard these patients as a failure of treatment. The remainder (approximately $70 \%$ ) were not seriously incapacitated after the period of conservative treatment, and in this group treatment is judged to have been successful.

\section{TABLE VI}

OVERALL RESULTS ${ }^{1}$

\begin{tabular}{|c|c|c|c|c|c|}
\hline \multicolumn{2}{|c|}{ Chronic Symjtoms } & \multicolumn{2}{|c|}{$\begin{array}{l}\text { Acute Symptoms Measured } \\
\text { by Work Loss }\end{array}$} & \multicolumn{2}{|c|}{ Change of Work } \\
\hline $\begin{array}{l}\text { Moderate or } \\
\text { Severe }\end{array}$ & $\begin{array}{l}\text { Mild or } \\
\text { Absent }\end{array}$ & $\begin{array}{l}4 \text { Weeks/ } \\
\text { Year }\end{array}$ & $\begin{array}{c}\text { Nil or }<4 \text { Weeks } \\
\text { Year }\end{array}$ & Yes & No \\
\hline $\begin{array}{l}32.4 \% \\
\text { Mean fol }\end{array}$ & $67.6 \%$ & $24 \%$ & $\begin{array}{c}76 \% \\
0-13 \text { years) }\end{array}$ & $29^{\circ}$ & $71 \%$ \\
\hline
\end{tabular}

The proportion of patients treated initially by conservative means and who eventually require surgery varies considerably according to the authority. Armstrong (1965) gives the figure for many orthopaedic surgeons as between $2 \%$ and $5 \%$, although in his own opinion the precentage is much higher, namely between $10 \%$ and $20 \%$. According to Brain (1962), the surgical referral rate is probably not more than $10 \%$. As shown previously (Table V), $7 \%$ of our own series eventually underwent late surgery, but in addition several patients required early surgery (for the indications already outlined).

There is no evidence to suggest that an acutely protruded lumbar disc ever regains its normal position. It is probable that the relief of pain is due to a subsidence of root sleeve oedema, inflammatory changes, and fibrosis and ankylosis around the protruded disc substance. It is not clear precisely what role, if any, rest in bed has on the long-term healing process, but the prevention of spinal movements is of importance in the relief of the acutely painful symptoms. In about $70 \%$ of patients this treatment is satisfactory, and is preferable to other conservative measures by virtue of its simplicity and the almost total absence of complications. In the remaining $30 \%$ rest in bed proved to be of limited value. Since these patients did not obtain any consistent degree of relief from the other medical measures to which they were subjected it is tempting to suggest that they all required surgical intervention. However, as pointed out in the introduction, patients with lumbar disc lesions are very prone to a psychogenic exaggeration of their primary organic symptoms, and if the basis for the latter is a minor structural change not reversible by an operation then it is likely that their symptoms will be aggravated by such a procedure. Such patients are frequently encountered.

With this reservation we feel that patients not responding to a period of adequate and absolute rest in bed, especially with the persistence of limited straight leg raising or scoliosis, should be subjected to early surgery. Since our patients were unselected it is probable that about $10 \%$ to $20 \%$ of patients suffering an acute lumbar disc will require surgical treatment.

\section{SUMMARY}

An unselected group of 73 patients suffering an acute lumbar disc lesion has been studied and followed up after conservative treatment, for an average of eight years (range 0 to 13 years). In terms of persistence of pain, acute relapses, and working capacity, approximately $70 \%$ showed a satisfactory response and about $30 \%$ of patients showed a poor response to an initial period of absolute rest in bed.

It is suggested that many of the patients failing to respond to adequate rest in bed should be subjected 
to surgery providing that gross psychogenic symptoms are not a complicating factor.

We are grateful to Dr. Hugh Garland for permission and encouragement to study the patients. We thank Miss J. Berry and Miss P. Stollard for secretarial aid, and Dr. S. E. L. Borissow for helpful suggestions pertaining to this study.

\section{REFERENCES}

Armstrong, J. R. (1965). Lumbar Disc Lesions, 2nd ed., pp 224-255. Livingstone, Edinburgh

Bradford, F. K., and Spurling, R. G. (1947). The Intervertebral Disc with Special Reference to Rupture of the Annulus Fibrosus with Herniation of the Nucleus Pulposus. 2nd Ed. Thomas, Springfield, IIl-

Brain, Lord (1962). Diseases of the Nervous System, 6th ed., p. 702. Oxford University Press, London.

Colonna, P. C., and Friedenberg, Z. B. (1949). The disc syndrome: Results of conservative care of patients with positive myelograms. J. Bone Jt. Surg., 31.A., 614-618.

Decker, H. G., and Shapiro, S. W. (1957). Herniated lumbar intervertebral disks. Arch. Surg., 75, 77-84.

Dunning, H. A. (1946). Prognosis in so-called sciatic neuritis. Arch Neurol. Psychiat. (Chic.), 55, 573-577.

Ekvall, S. (1939). Enquête clinique, au printemps de 1938, sur les cas de sciatique observés durant les années 1933 et 1934. Acto med. scand., 101, 1-33.

Friberg, S., and Hirsch, C. (1950). Anatomical and clinical studies on lumbar disc degeneration. Acta orthop. scand., 19, 222-242.

Jennett, W. B. (1956). A study of 25 cases of compression of the cauda equina by prolapsed intervertebral discs. $J$. Neurol. Neurosurg. Psychiat., 19, 109-116.

- (1964). An Introduction to Neurosurgery, 1st ed., p. 269 et seq., Heinemann, London.

Kirsten, L. (1945). An after-examination of operated and nonoperated cases of patients with 'clinical symptoms of herniated disc'. Acta med. sicand., 120, 93-106.

Larson, C. B. (1957). Low back pain. DM (Chic.), May, pp. 1-34.

O'Connell, J. E. A. (1950). The indications for and results of the excision of lumbar intervertebral disc protrusions: A review of 500 cases. Ann. roy. Coll. Surg. Engl., 6, 403-412.
Roseman, E. (1958). Pain associated with protruded intervertebral disks. Med. Clin. N. Amer., 42, 1567-1588.

Saunders, J. B., and Inman, V. T. (1940). Pathology of the intervertebral disc. Arch. Surg., 40, 389-416.

Spurling, R. G., and Grantham, E. G. (1949). The end-results of surgery for ruptured lumbar intervertebral discs. J. Neurosurg., 6, 57-64.

\section{APPENDIX}

\section{QUESTIONNAIRE SENT TO PATIENTS IN GROUP B}

Please carefully fill in the answers to the following questions, to help us assess the results of your treatment. Tick the appropriate answers.

1 Have you had further pain in the back, buttocks or legs since treatment. YES.... or NO..... If the answer is YES fill in the following questions.

2 Has the pain been MILD.... MODERATE.... or SEVERE....

3 Has the pain caused loss of time from work. YES... . or NO..... If so for how many weeks per year on average, Less than 4 weeks....4 to 8 weeks.... More than 8 weeks.....

4 Have you had further treatment since being discharged from this hospital. YES.... or NO.....

5 If YES to Question 4, did you have:Spinal support (corset).... A period of rest in bed Traction Operation

6 Are you doing the same work or a similar type of work as you were doing before you developed your symptoms. YES .... or NO .....

7 Are your present wages the same..., more...., or less.... than before. If less, how much less do you now earn each week........ Your own comments or observations:- 